\title{
Occurrence of the vanA gene in Staphylococcus epidermidis from nasopharyngeal secretion of Health-Care Workers, Recife, Brazil
}

\author{
Armando Monteiro Bezerra Neto ${ }^{[1]}$, Marcelle Aquino Rabelo ${ }^{[1]}$, Jailton Lobo da Costa \\ Lima $^{[1]}$, Stéfany Ojaimi Loibman ${ }^{[2]}$, Nilma Cintra Leal ${ }^{[3]}$ \\ and Maria Amélia Vieira Macie[ [1],14]
}

\begin{abstract}
[1]. Programa de Pós-Graduação em Medicina Tropical, Departamento de Medicina Tropical, Universidade Federal de Pernambuco, Recife, PE, Brasil.
[2]. Centro de Biociências, Universidade Federal de Pernambuco, Recife, PE, Brasil.

[3]. Departamento de Microbiologia, Centro de Pesquisa Aggeu Magalhães, Fundação Oswaldo Cruz-PE, Recife, PE, Brasil.

[4]. Departamento de Microbiologia, Centro de Ciências da Saúde, Universidade Federal de Pernambuco, Recife, PE, Brasil.
\end{abstract}

\begin{abstract}
Introduction: The increasing reports of vancomycin-resistant Staphylococcus strains (VRS) haves caused concern worldwide, from the laboratory detection to patient management. This study aimed to identify the occurrence of VRS strains among healthcare professionals from a university hospital. Methods: A total of 102 Staphylococcus $s p$. isolates from healthcare professionals, obtained in a previous study were evaluated according to standard techniques for VRS detection. Results: After screening inoculation of plates containing $6 \mu \mathrm{g} / \mathrm{ml}$ of vancomycin, 19 resistant isolates were identified. The susceptibility profile to other antimicrobials revealed 18 multidrug resistant isolates. The minimum inhibitory concentration (MIC) was determined by E-test and broth microdilution. According to E-tests, of 19 isolates grown in BHI-V6, four isolates presented MIC $\geq 128 \mu \mathrm{g} / \mathrm{ml}$, seven with MIC ranging from 4 to $8 \mu \mathrm{g} / \mathrm{ml}$, and eight with $\mathrm{MIC} \leq 2 \mu \mathrm{g} / \mathrm{ml}$. By broth microdilution, 14 isolates presented MIC $\leq 2 \mu \mathrm{g} /$ $\mathrm{ml}$ and five with MIC $\geq 16 \mu \mathrm{g} / \mathrm{ml}$. The presence of the gene $v a n A$ was determined by PCR in the five resistant isolates, and this gene was detected in one of the strains. Furthermore, among the 19 strains, the gene mecA was found in $13(39,4 \%)$ isolates, including the strain carrying the gene vanA. Conclusions: Based on these results, we highlight the presence of one strain carrying both van $A$ and the $m e c A$ genes, as well as multidrug-resistant strains colonizing healthcare professionals, and their importance as potential vectors to spread strains carrying resistance genes in the hospital environment.
\end{abstract}

Keywords: Staphylococcus. Healthcare professionals. Vancomycin. Multiresistance. Methicillin.

\section{INTRODUCTION}

Infections due to methicillin-resistant staphylococcal strains (MRS) present increased risk of treatment failure, and for some time glycopeptides, such as vancomycin and teicoplanin, have been the only therapeutic option, which justifies the crescent use of this class of drugs ${ }^{1,2}$. Some antimicrobials that exhibit in vitro activity against Staphylococcus aureus remain active against strains resistant to glycopeptides such as rifampicin and fusidic acid $^{3}$. In recent years, a limited number of new antimicrobials have been developed. Among them, the $5^{\text {th }}$ generation cephalosporins, ceftaroline and ceftobiprole have been shown to be effective against MRSA isolates ${ }^{4}$. Other antimicrobials not

Corresponding author: Msc. Armando Monteiro Bezerra Neto. e-mail: monteiro.armando10@gmail.com

Received 4 May 2017

Accepted 6 June 2018 belonging to the group of beta-lactams and with activity against these micro-organisms, including linezolid, daptomycin and tigecycline, have been available since the beginning of the $21^{\text {st }}$ century and are widely employed in clinical practice 5 .

The indiscriminate use of vancomycin therapy to treat hospital infections has allowed for the emergence of $S$. aureus isolates and other staphylococcal species with reduced sensitivity to vancomycin and other glycopeptides ${ }^{6}$, such as vancomycin/ glycopeptide intermediate resistant $S$. aureus (VISA/GISA) and vancomycin/glycopeptide resistant $S$. aureus (VRSA/GRSA) ${ }^{3}$. Studies have reported an increased number of glycopeptideresistant Staphylococcus epidermidis (GRSE) worldwide?

Isolates of $S$. aureus, especially coagulase-negative Staphylococci (CoNS) resistant to methicillin/oxacillin isolates, with reduced susceptibility to glycopeptides have been reported in Japan, the United States (US), Europe, and Asia since the end of the $80 \mathrm{~s}^{3}$. In 1997, two major categories of vancomycinresistant $S$. aureus had been defined: (1) vancomycin-resistant $S$. aureus (VRSA), carrying the vanA gene, mediating 
high-level resistance (MIC $\geq 16 \mu \mathrm{g} / \mathrm{ml}$ ) and (2) vancomycinintermediate $S$. aureus (VISA) isolates with low-level resistance (MIC $\geq 4$ to $<16 \mu \mathrm{g} / \mathrm{ml}$ ) by cell wall thickening 8 .

In Brazil, staphylococcal strains with reduced susceptibility to glycopeptides were reported in hospitals in São Paulo and Rio de Janeiro a decade ago ${ }^{9}$, and recently $S$. aureus containing the van $A$ and vanB genes were described in Brazil ${ }^{10,11}$.

Colonization of diverse body sites by CoNS, and transient colonization by $S$. aureus, can be a source of infection for immunocompromised patients ${ }^{12}$, highlighting microbiota colonization of health professionals as a source of dissemination of health care-associated infections (HAIs) ${ }^{13}$.

The transmission chain of antimicrobial resistant microorganisms in the hospital environment involves health professionals as potential source of transmission to patients, coworkers, family and community, emphasizing their importance in the context of the HAIs ${ }^{13,14}$.

In Brazil, resistant phenotypic profiles of different Staphylococcus species, with reduced resistance to vancomycin, were detected in microbiota samples of asymptomatic carriers 12. Considering that Staphylococcus species are important pathogens associated with HAIs and there are few studies regarding vancomycin resistance in the colonizing microbiota of health professionals, the aims of this research were to identify the microorganisms colonizing the nasopharynx of health professionals and analyze the vancomycin resistance profile of these isolates by phenotypic and genetic methods.

\section{METHODS}

\section{Study design and bacterial samples}

An experimental-based study was carried out in April to December 2014 with staphylococcal isolates obtained in a previous study ${ }^{15}$, originated from nasopharyngeal secretions of healthcare professionals of three sectors of the University Hospital of Pernambuco, Brazil: Intensive Care Unit (ICU), Surgical Clinics, and Hemodialysis Service/Nephrology.

A total of 102 Staphylococcus strains-kept as frozen stock in Brain Heart-Infusion (BHI) broth supplemented with glycerol $(20 \%)$ at $-20^{\circ} \mathrm{C}$ and in nutrient agar slants at $4^{\circ} \mathrm{C}$-were placed in $\mathrm{BHI}$ broth, inoculated in 5\% sheep blood agar, and incubated for $24-48 \mathrm{~h}$ at $35^{\circ} \mathrm{C}$. Colonies with macroscopic characteristics of the genus Staphylococcus were Gram stained. Following confirmation by morphology and staining, colonies were submitted for identification using deoxyribonuclease (DNase), catalase and coagulase tests, and manitol fermentation. The identification of the staphylococcal species was made through the automated system VITEK 2. Based on these readings, profile identification was established and interpreted according to a specific algorithm. The result of the profile was compared with the database, generating the identification of the unknown organism.

\section{Vancomycin susceptibility testing}

The isolates were screened by vancomycin susceptibility test using BHI supplemented with $6 \mu \mathrm{g} / \mathrm{mL}$ of vancomycin (BHI-V6). Inoculums were adjusted to $0.5 \mathrm{McF}$ arland turbidity ${ }^{3}$.
Two methods were used to determine the MIC to vancomycin: broth microdilution and E-test (BIOMÉRIEUX), according to Clinical and Laboratory Standards Institute (CLSI) guidelines ${ }^{16}$. One clinical isolate of Enterococcus faecium harboring the vanA gene was used as a positive control ${ }^{17}$ and the Enterococcus faecalis (ATCC 29212) strain as the negative control. The E-test was performed using a suspension of $0.5 \mathrm{McF}$ arland turbidity plated onto Müller-Hinton medium and incubated at $35^{\circ} \mathrm{C}$ for $24 \mathrm{~h}$. The interpretation was performed according to manufacturer's specifications and compared to CLSI cut off values ${ }^{3}$.

For determination of MIC by Broth Microdilution, it was determined manually in Mueller Hinton broth, according to the recommendations of the $\mathrm{CLSI}^{16}$. Assays for vancomycin were performed in medium supplemented with $\mathrm{Ca} 2+(50 \mathrm{mg} / \mathrm{L})$. Initial inoculums of bacteria $\left(0.5 \times 10^{5} \mathrm{CFU} / \mathrm{mL}\right)$ were plated onto 96-well polypropylene plates, exposed to 8 dilutions $(1 \mu \mathrm{g} / \mathrm{mL}$ to $128 \mu \mathrm{g} / \mathrm{mL})$ of the tested compound, and incubated for $18 \mathrm{~h}$ at $35^{\circ} \mathrm{C}$. The minimum inhibitory concentration was taken as the lowest concentration of the compound in which no visible bacterial growth was observed. According to CLSI recommendations, the bacterial isolates were categorized as resistant or susceptible using interpretive criteria ${ }^{16}$.

Agreement between E-test and microdilution was defined as minimum inhibitory concentrations (MICs) that differed by \pm $1-\log 2$ dilutions or less. Categorical agreement was defined as test results within the same susceptibility. Errors were ranked as follows: very major error, false-susceptible result by the E-test; major error, false-resistant result produced by the E-test; and minor error, intermediate result by E-test method and a resistant or susceptible category for the reference method (microdilution test), according to CLSI guidelines ${ }^{19}$.

\section{Antimicrobial susceptibility testing}

The Staphylococcus isolates were tested by disc diffusion in Mueller-Hinton agar, according to the CLSI guidelines ${ }^{18}$, using the following antibiotics: penicillin (10U), gentamicin $(10 \mu \mathrm{g})$, clindamycin $(2 \mu \mathrm{g})$, sulfazotrim $(1.25 / 23.75 \mu \mathrm{g})$, ciprofloxacin $(5 \mu \mathrm{g})$, chloramphenicol $(30 \mu \mathrm{g})$, cefoxitin $(30 \mu \mathrm{g})$, erythromycin $(15 \mu \mathrm{g})$, and linezolid $(5 \mu \mathrm{g})$. After incubation for 24 hours at $35^{\circ} \mathrm{C}$, the inhibition zones were measured using a caliper.

\section{Concordance scale analysis of phenotypic vancomycin susceptibility tests}

The agreement between the phenotypic tests to assess the vancomycin resistance profile were verified by the $\mathrm{k}$ (kappa) index ${ }^{20}$.

\section{Molecular techniques}

Deoxyribonucleic acid (DNA) was extracted as described by Oliveira ${ }^{21}$ from vancomycin-resistant isolates detected by the different phenotypic techniques. Subsequently, it was used in polymerase chain reaction (PCR) for amplification of the genes vanA and mecA. PCR was performed using the primers and conditions as previously described (forward-5' -TGAATAACATCGGCATTAC-3' and reverse-5' -TTATTTAACGGGGAAATC-3') ${ }^{22}$ and (P1 5'-GGTCCCATTAACTCTGAAG-3' and P3 5'-AGTTCTGCAGTACCGGATTTGC-3' $)^{23}$. 


\section{Sequencing of vanA gene}

A positive PCR product for the vanA gene was purified by the Wizard $₫$ SV Gel kit and PCR Clean-Up System (Promega) according to the manufacturer's protocol. Following, it was quantified by spectrophotometry using the software Chromas Lite 2.1.1, Basic Local Alignment Research Tool (BLAST), and Expert Protein Analysis System (ExPASy) algorithm. The analyzed sequences of vanA were deposited in GenBank with the following accession number: KT581638.

\section{RESULTS}

In this study, we analyzed 102 isolates collected from health professionals, 31.4\% (32/102) S. aureus and 68.6\% (70/102) CoNS isolates. Approximately $43.1 \%$ (44/102) of the isolates were from the Surgical/Infectious and Parasitic Diseases sector, of which $22.7 \%$ (10/44) were S. aureus and $77.3 \%(34 / 44)$ were CoNS. Isolates from the ICU represented $20.6 \%$ (21/102), of which $38 \%$ (8/21) were $S$. aureus and 62\% (13/21) were CoNS.

Concerning the vancomycin susceptibility, seven out of 19 isolates were $S$. aureus and $12 \mathrm{CoNS}$, which grew at the vancomycin screening test at a concentration of $6 \mu \mathrm{g} / \mathrm{mL}$ (BHI-V6).
The susceptibility profile to other antimicrobials showed that 18 isolates presented resistance to more than three classes of antimicrobials and were considered multi-drug resistant (MDR) strains. It is worth noting that 16 were resistant to erythromycin. Of these, 11 were also resistant to clindamycin, indicating resistance to macrolides, lincosamide, and streptogramin-B.

All 19 resistant strains, previously detected by the screening test, were evaluated by E-test for quantitative determination of the MIC to vancomycin. The seven isolates of $S$. aureus presented the following MIC ranges: two isolates with $\mathrm{MIC} \leq 2 \mu \mathrm{g} / \mathrm{mL}$ (sensitive), three with MIC between 4 and $8 \mu \mathrm{g} / \mathrm{mL}$, and two with MIC $>256 \mu \mathrm{g} / \mathrm{mL}$. In addition, of the $12 \mathrm{CoNS}, 10$ isolates presented $\mathrm{MIC} \leq 4 \mu \mathrm{g} / \mathrm{mL}$ and two isolates $\mathrm{MIC} \geq 128 \mu \mathrm{g} / \mathrm{mL}$.

According to the MIC values obtained by broth microdilution, of the seven S. aureus isolates, five were sensitive (MIC $\leq 2 \mu \mathrm{g} /$ $\mathrm{mL}$ ) and two were resistant (MIC $\geq 16 \mu \mathrm{g} / \mathrm{mL})$. Regarding the 12 CoNS isolates, nine showed $\mathrm{MIC} \leq 2 \mu \mathrm{g} / \mathrm{mL}$ and three MIC $\geq 32 \mu \mathrm{g} / \mathrm{mL}$, as shown in Table 1 .

The kappa index coefficient of 0.96 was obtained by comparing the E-test to Broth Microdilution, indicating very good agreement between these two methods.

TABLE 1: Susceptibility profile of the Staphylococcus isolates.

\begin{tabular}{|c|c|c|c|c|c|c|c|}
\hline $\begin{array}{l}\text { Bacterial } \\
\text { species }\end{array}$ & Susceptibility profile & $\begin{array}{l}\text { Cefoxitin disc- } \\
\text { diffusion }\end{array}$ & BHI-V6 & $\begin{array}{c}\text { E-test ( } \mu \mathrm{g} / \\
\mathrm{mL})\end{array}$ & $\begin{array}{c}\text { Broth } \\
\text { microdiluition } \\
(\mu \mathrm{g} / \mathrm{mL})\end{array}$ & Gene vanA & $\begin{array}{l}\text { Gene } \\
\text { mecA }\end{array}$ \\
\hline S. aureus & PEN, CLI, CFO, ERY & $\mathrm{R}$ & + & 4 & 2 & - & - \\
\hline S. aureus & PEN, CLI, GM, CFO, RIF, ERY, CIP & $\mathrm{R}$ & + & 1 & 1 & - & - \\
\hline S. aureus & PEN, CHL, CFO, ERY & $\mathrm{R}$ & + & 4 & 2 & - & - \\
\hline S. aureus & PEN, CLI, CFO, LZD, RIF, ERY, CIP & $\mathrm{R}$ & + & $>256$ & 32 & - & - \\
\hline S. aureus & PEN, CIP & $\mathrm{R}$ & + & 2 & 2 & - & + \\
\hline S. aureus & PEN, GM, CFO, ERY, CIP & $\mathrm{R}$ & + & 4 & 1 & - & - \\
\hline CoNS & PEN, CLI, SUF, CHL, CFO, ERY & $\mathrm{R}$ & + & 128 & 128 & - & + \\
\hline CoNS & CLI, CHL, GM, CFO, ERY, CIP & $\mathrm{R}$ & + & 2 & 2 & - & + \\
\hline CoNS & CLI, GM, CFO, ERY, CIP & $\mathrm{R}$ & + & 4 & 2 & - & + \\
\hline CoNS & PEN, CLI, CFO, ERY, CIP & $\mathrm{R}$ & + & 4 & 2 & - & + \\
\hline CoNS & PEN, CLI, CFO, ERY, CIP & $\mathrm{R}$ & + & 2 & 2 & - & + \\
\hline CoNS & PEN, SUF, CFO, ERY & $\mathrm{R}$ & + & $>256$ & 32 & + & + \\
\hline CoNS & PEN, CLI, SUF, GM, CFO, RIF, ERY, CIP & $\mathrm{R}$ & + & 2 & 2 & - & + \\
\hline CoNS & CFO, LZD, CIP & $\mathrm{R}$ & + & 2 & 2 & - & - \\
\hline CoNS & PEN, CLI, CHL, CFO, ERY, CIP & $\mathrm{R}$ & + & 2 & 2 & - & + \\
\hline
\end{tabular}

BHIV6: brain heart infusion agar; vanA: gene; mecA: gene; S.: Staphylococcus; CoNS: coagulase-negative Staphylococci; PEN: penicillin; CLI: clindamycin; CFO: cefoxitin; ERY: erythromycin; GM: gentamicina; RIF: rifampicin; CIP: ciprofloxacin; CHL: chloramphenico; LZD: linezolide; SUF: sulfazotrim; R: resistant; +: growth; -: growth. 
The agreement within 1 two-fold dilution between E-test and the broth microdilution reference method was $84 \%$. Seven (36\%) minor errors were found comparing E-test with microdilution in broth for vancomycin. There was no occurrence of major or very major errors. The categorical concordance was $93 \%$.

Of the five isolates with MICs considered resistant, only one isolate ( $S$. epidermidis) carried the vanA gene, which was confirmed by sequencing and showed $100 \%$ of similarity with ten sequences from Enterococcus deposited in GenBank (KT581638).

In parallel to obtaining vancomycin susceptibility, a cefoxitin susceptibility test was performed using the disc-diffusion technique, from which it was possible to observe that all the isolates were resistant to cefoxitin. After the disc-diffusion cefoxitin test, the presence of the $m e c A$ gene was investigated.

In order to genetically characterize these isolates, $m e c A$ gene detection was performed by PCR, and the gene was found in 13/19 (39.4\%) isolates, including one isolate of $S$. aureus (MRSA) from the Nephrology/Hemodialysis Service sector. Of the 12 MRCoNS, five were obtained from the Nephrology/ Hemodialysis Service sector, four from Surgical/Infectious and Parasitic Diseases sector, and three from ICU. The isolate that presented the gene vanA also exhibited the gene mecA. As for the remaining noncarrier isolates of the $v a n A$ gene, five contained the mec $A$ gene (all MRCoNS) and 13 did not present this gene (6 MSCoNS and 7 MSSA).

\section{DISCUSSION}

In this study, we found a higher incidence of $m e c A$ gene in CoNS strains. Regarding the susceptibility profile analyses, the MRS strains were more resistant to multiple classes of antimicrobial agents than MRSA. Similar results were obtained by Costa ${ }^{4}$, however, Fadeyi ${ }^{25}$ described MDR in MRSA isolates colonizing the nasopharynx of health professionals in Nigeria.

The studies regarding the analysis of susceptibility to vancomycin started approximately three decades ago, when environmental strains of $S$. aureus were detected with reduced susceptibility (intermediate) to this $\operatorname{drug}^{26}$. Additionally, the emergence of hetero-VRSA strains occurred in the 80 s after the introduction of vancomycin use for treatment of staphylococcal infections in Japan ${ }^{27}$. Several research studies related to the molecular analysis of heteroresistance vancomycin-intermediate $S$. aureus worldwide have been performed, following associations of these strains with persistent infections and treatment failure ${ }^{28}$.

Results of MIC to vancomycin evaluated by E-test and broth microdilution techniques demonstrated divergence. Three isolates of $S$. aureus showed MICs between 4 and $8 \mu \mathrm{g} / \mathrm{mL}$ (VISA) with the microdilution method but no isolates presented similar MIC with E-test. In addition, this technique is a screening tool for heterogeneous VISA (hVISA) and VISA, but does not apply to vancomycin or teicoplanin, and the results obtained with this technique should not be reported as true $\mathrm{MIC}^{29}$.

In the present study, four resistant vancomycin isolates (two VRSA and two VRS) were detected by both the E-test and broth microdilution. There was reasonable correlation between these two methods. Using comparisons between Broth Microdilution and E-test MICs results for vancomycin, it was possible to observe that essential and categorical agreements presented at $84 \%$ and $93 \%$, respectively. Yet, a minor error of $36 \%$ was detected: however, major error and very major error were $0 \%$.

Genetic characterization these vancomycin resistant isolates was performed by PCR for the vanA gene. During the period that the present study was conducted, vancomycin resistance was not described in other genes in $\mathrm{Brazil}^{10}$. Among the isolates only one harbored the vanA gene, which was a specific isolate Staphylococcus epidermidis from HCW microbiota.

The presence of the vanA gene was not found in the four resistant vancomycin strains (VRSA and VRS), as a result, the precise genetic mechanism for vancomycin resistance in these staphylococcal strains awaits elucidation. The cell wall thickening has been reported for glycopeptide-resistant VRS and VRSA ${ }^{12,17,28}$.

The nasopharynx microbiota of health professionals harboring resistant strains to vancomycin have already been described in the literature ${ }^{13,31}$; however, the first Brazilian report of $S$. epidermidis, harboring the vanA gene, and colonizing a health professional from ICU occurred at an University Hospital in Recife, Brazil ${ }^{12}$. Breves ${ }^{11}$ reported the occurrence of one $S$. aureus isolate obtained from the hands of a health professional, which harbored resistance genes to vancomycin $(\mathrm{vanB})$ and methicillin (mecA). On the other hand, there are many studies reporting methicillin-resistant staphylococcal isolates from nasopharyngeal of health professionals and microbiota of patients $^{32-34}$.

Cases reports regarding microbiota colonization of vancomycin-resistant staphylococcal strains obtained from patients at clinics or hospitals are scarce. In India, two studies have reported patients harboring $S$. aureus with the vanA gene $^{35,36}$.

The occurrence of HAIs caused by Staphylococcus isolates carrying the vanA gene has been reported worldwide, associated with different patterns of infections, mainly in the US and in Brazil $^{11,22,37-41,24}$.

Some studies correlate methicillin resistance to vancomycin tolerance due to vancomycin treatment failures in cases of infections caused by methicillin-resistant microorganisms ${ }^{7,42-44}$. In 2006, three strains were reported, two $S$. aureus and one CoNS, with resistance to both antibiotics vancomycin and methicillin ${ }^{45}$.

A potential emergence of vancomycin resistance may occur in hospitals in Brazil, as reported in recent studies ${ }^{9,28}$. This suggests the need for constant monitoring of susceptibility patterns to vancomycin, application of molecular methods and heteroresistance detection, as well as adoption of control measures to avoid the spread of these strains in the hospital environment.

\section{Acknowledgments}

We thank our collaborator Dr. Marcia Maria Camargo de Morais who provided the positive control enterococcal strain for the vanA gene. 


\section{Financial support}

This work was financially supported by Fundação de Amparo Ciência do Estado de Pernambuco (FACEPE) to MAVM (Process APQ 0579-2.12/06) and the Conselho Nacional Cientifico e Tecnológico (CNPq) Grant to MAVM (Process \#474131/2011-4).

\section{Conflict of interest}

The authors declare that there is no conflict of interest.

\section{REFERENCES}

1. Burnham CAD, Weber CJ, Dunne Jr WM. Novel screening agar for detection of vancomycin-nonsusceptible Staphylococcus aureus. J Clin Microbiol. 2010;48(3):949-51.

2. Melo GB, Melo MC, Carvalho KS, Gontijo Filho PP. Vancomycinresistant Staphylococcus aureus and coagulase-negative staphylococci in a Brazilian University Hospital. J Bas Appl Pharma Scien. 2009;30(1):55-61.

3. Howden BP, Davies JK, Johnson PDR, Stinear TP, Grayson ML Reduced vancomycin susceptibility in Staphylococcus aureus, including vancomycin-intermediate and heterogeneous vancomycinintermediate strains: resistance mechanisms, laboratory detection and clinical implications. Clin Microbiol Rev. 2010;23(1):99-139.

4. Batista BG, Rauber JM, Bruschi JS, d'Azevedo PA. New cephalosporin as an alternative for treatment of infections by methicillin-resistant Staphylococcus aureus (MRSA). Rev Epidemiol Control Infect. 2015;5(2):94-9.

5. Rodvold KA, McConeghy KW. Methicillin-resistantStaphylococcus aureus therapy: past, present, and future. Clin Infect Dis. 2014;58(Suppl 1):S20-7.

6. Thati V, Shivannavar CT, Gaddad SM. Vancomycin resistance among methicillin-resistant Staphylococcus aureus isolates from intensive care units of tertiary care hospitals in Hyderabad, Indian J Med Res. 2011;134(5):704-8.

7. Cremniter J, Slassi A, Quincampoix JC, Tardy VS, Bauer T, Porcher $\mathrm{R}$, et al. Decreased susceptibility to teicoplanin and vancomycin in coagulase-negative staphylococci isolated from orthopedic-deviceassociated infections. J Clin Microbiol. 2010;48(4):1428-31.

8. Vaudaux P, Huggler E, Bernard L, Ferry T, Renzoni A, Lew DP. Underestimation of vancomycin and teicoplanin MICs by broth microdilution leads to underdetection of glicopeptide-intermediate isolates of Staphylococcus aureus. Antimicrob Agents Chemother. 2010;54(9):3861-70.

9. Melo G B, Melo MC, Gama AP, Carvalho KS, Jesus, TC, Bonetti AM, Gotijo Filho PP. Analysis of the genetic diversity of vancomycin-resistant Staphylococcus aureus. Braz J Microbiol. 2005;36(2):126-30.

10. Rossi FMD, Diaz L, Wollam A, Panesso D, Zhou Y, Rincon S, et al. Transferable vancomycin resistance in a community-associated MRSA lineage. N Eng1 J Med. 2014;370(16):1524-31.

11. Breves A, Miranda CAC, Flores C, Filippis I, Clementino MM. Methicillin- and vancomycin-resistant Staphylococcus aureus in health care workers and medical device. Braz J Pathol Lab Med. 2015;51(3):143-52.

12. Palazzo ICV, Araujo MLC, Darini ALC. First report of vancomycinresistant staphylococci isolated from healthy carriers in brazil. J Clin Microbiol. 2005;43(1):179-85.

13. Rabelo MA, Bezerra Neto AM, Silva ECBF, Oliveira WLM, Melo FL, Lopes ACS, et al. Phenotypic methods for determination of methicillin resistance in Staphylococcus spp. from health care workers. Braz J Pathol Lab Med. 2013;49(2):91-6.

14. Silva ECBF, Maciel MAV, Melo FL, Lopes ACS, Arca IS. Epidemiological surveillance and susceptibility of Staphylococcus aureus among healthcare workers at a reference hospital: preliminary assessment. Rev Inst Adolfo Lutz. 2010;69(1):126-30.

15. Rabelo MA, Bezerra Neto AM, Loibman SO, Lima JLC, Ferreira EL, Leal NC, et al. The occurrence and dissemination of methicillin and vancomycin-resistant Staphylococcus in samples from patients and health professionals of a university hospital in Recife, State of Pernambuco, Brazil. Rev Soc Bras Med Trop. 2014;47(4):437-46.

16. Clinical and Laboratory Standards Institute. CLSI M07-A9 Methods for dilution antimicrobial susceptibility tests for bacteria that grow aerobically; approved standard. CLSI document M07-A9. Wayne, PA: CLSI; 2012.

17. Vilela MA, Souza SL, Palazzo ICV, Ferreira JC, Morais Jr. MA, Darini ALC, et al. Identification and molecular characterization of Van A-type vancomycin-resistant Enterococcus faecalis in Northeast of Brazil. Mem Inst Oswaldo Cruz. 2006;101(7):716-9.

18. Clinical and Laboratory Standards Institute. CLSI M100-S24 Performance Standards for Antimicrobial Susceptibility Testing - Twenty-Sixth Informational Supplement. CLSI document M100-S24. Wayne, PA: CLSI; 2014.

19. Clinical and Laboratory Standards Institute. CLSI M23-A5 Development of In Vitro Susceptibility Testing Criteria and Quality Control Parameters, 5th Edition, document M23-A5 Wayne, PA: CLSI; 2018.

20. Organização Pan-Americana da Saúde (PAHO). Fundação Nacional de Saúde/Centro Nacional de Epidemiologia. Métodos de Investigação Epidemiológica em Doença Transmissíveis. Volume I. Brasília: PAHO; 1997. 135p.

21. Oliveira WLM, Mangueira EVC, Vilela MA, Paiva Júnior S, Leal NC, Almeida AMP. Diversity of Sccmec types in ant Staphylococcus spp. causing Hospital-Associated Infections. J J Microbiol Pathol. 2015;2(3):020.

22. Saha B, Singh AK, Ghosh A, Bal M. Identification and characterization of a vancomycin-resistant Staphylococcus aureus isolated from Kolkata (South Asia). J Med Microbiol. 2008;57:72-9.

23. Petinaki E, Arvaniti A, Dimitracopoulos G, Spiliopoulou I. Detection of mecA, mecRl and mecI genes among clinical isolates of methicillin-resistant staphylococci by combined polymerase chain reactions. J Antimicrob Chemother. 2001; 47(3):297-303.

24. Costa DM, Kipnis A, Vasconcelos LSL, Vilefort LOR, Telles S A, André MC, et al. Staphylococcus sp. colonizing health care workers of a cancer hospital. Braz J Microbiol. 2014;45(3):799-805.

25. Fadeyi A, Bolaji BO, Oyedepo OO, Adesiyun OO, Adeboye MAN, Olanrewaju TO, et al. Methicilin resistant Staphylococcus aureus carriage amongst Healthcare Workers of the Critical Care Units in a Nigerian Hospital. Am J Infect Dis. 2010;6(1):18-23.

26. Hiramatsu K. Vancomycin-resistant Staphylococcus aureus: a new model of antibiotic resistance. Lancet Infect Dis. 2001;1(3):147-55.

27. Watanakukorn C. Mode of action and in-vitro activity of vancomycin. J Antimicrob Chemother. 1984;14(Suppl D):7-18.

28. Silveira ACO, Cunha GR, Caierão J, Cordova CMM, D'azevedo PA. Molecular epidemiology of heteroresistant vancomycinintermediate Staphylococcus aureus in Brazil. Braz J Infect Dis. 2015;19(5):466-72.

29. Prakash V, Lewis JS, Jorgensen JH. Vancomycin MICs for methicillin-resistant Staphylococcus aureus isolates differ based upon the susceptibility test method used. Antimicrob. Agents Chemother. 2008;52(12):4528. 
30. Cui L, Ma X, Sato K, Okuma K, Tenover FC, Mamizuka EM, Gemmell CG, Kim MN, Ploy MC, El-Solh N, Ferraz V, Hiramatsu K. Cell wall thickening is a common feature of vancomycin resistance in Staphylococcus aureus. J Clin Microbiol. 2003;41:5-14.

31. Daef EA, Elsherbiny NM, Ibrahim MA, Ahmed EH. Decolonization of Methicillin resistant Staphylococcus areus Nasal Carriage Among Health Care Workers. Life Scien J. 2012;9(4):4496-501.

32. Saito G, Thom J, Wei Y, Gnanasuntharam P, Kreiswirth N, Willey B, et al. Methicillin-resistant Staphylococcus aureus colonization among health care workers in a downtown emergency department in Toronto, Ontario. Can J Infect Dis Med Microbiol. 2013;24(3):57-60.

33. Ruiz A, Mora M, Zurita C, Larco D, Toapanta Y, Zurita J. Prevalence of methicillin-resistant Staphylococcus aureus among health care workers of intensive care units in Ecuador. J Infect Dev Ctries. 2014;8(1):116-19.

34. Goud R, Gupta S, Neogi U, Agarwal D, Naidu K, Chalannavar R, Subhaschandra G. Community prevalence of methicillin and vancomycin resistant Staphylococcus aureus in and around Bangalore, southern India. Rev Soc Bras Med Trop. 2011;44(3):309-12.

35. Banerjee T, Anupurba S. Colonization with VancomycinIntermediate Staphylococcus aureus strains containing the vanA resistance gene in a Tertiary-Care Center in North India. J Clin Microbiol. 2012;50(5):1730-32.

36. Center for Disease Control and Prevention (CDC). Staphylococcus aureus resistant to vancomycin - United States, 2002. Morb Mortal Wkly Rep MMWR. 2002;51:565-7.

37. Chang S, Sievert DM, Hageman JC, Boulton ML, Tenover FC, Downes FP, et al. Infection with vancomycin-resistant Staphylococcus aureus containing the vanA resistance gene. N Engl J Med. 2003;348(14):1342-47.
38. Aligholi M, Emaneini M, Jabalameli F, Shahsavan S, Dabiri $\mathrm{H}$, Sedaght H. Emergence of high-level vancomycin-resistant Staphylococcus aureus in the Imam Khomeini Hospital in Tehran. Med Princ Pract. 2008;17(5):432-4.

39. Sievert DM, Rudrick JT, Patel JB, McDonald LC, Wilkins MJ, Hageman JC. Vancomycin-resistant Staphylococcus aureus in United States, 2002-2006. Clin Infect Dis. 2008;46(5):668-74.

40. Foucault ML, Courvalin P, Grillot-Courvalin C. Fitness cost of vanAtype vancomycin resistance in methicillin-resistant Staphylococcus aureus. Antimicrob Agents Chemother. 2009;53(6):2354-9.

41. Perichon B, Courvalin P. VanA-type vancomycin-resistant Staphylococcus aureus. Antimicrob Agents Chemother. 2009;53(11):4580-7.

42. Soriano A, Marco F, Martínez JA, Pisos E, Almela M, Dimova VP, et al. Influence of vancomycin minimum inhibitory concentration on the treatment of methicillin-resistant Staphylococcus aureus bacteremia. Clin Infect Dis. 2008;46(2):193-200.

43. Kos VN, Desjardins CA, Griggs A, Cerqueira G, Van Tonder A, Holden MTG, et al. Comparative genomics of vancomycin-resistant Staphylococcus aureus strains and their positions within the clade most commonly associated with methicillin-resistant $S$. aureus hospital-acquired infection in the United States. mBio. 2012;3(3):e00112-12.

44. Domínguez VC, Córdova AC, Ochoa AS, Escalona G, Galindo JA, Leviz AR, Castro RH, et al. Vancomycin tolerant, methicillinresistant Staphylococcus aureus reveals the effects of vancomycin on cell wall thickening. PLoS One. 2015;10(3):1-16.

45. Tiwari HK, Sen MR. Emergence of vancomycin resistant Staphylococcus aureus (VRSA) from a tertiary care hospital from northern part of India. BMC Infect Dis. 2006;6(156):1-6. 